\title{
The Relevance of Basophil Allergen Sensitivity Testing to Distinguish between Severe and Mild Peanut-Allergic Children
}

\author{
Matjaž Homšak $^{a}$ Mira Šilar $^{b}$ Vojko Berce $^{a}$ Maja Tomazin $^{a}$ \\ Maja Skerbinjek-Kavalar ${ }^{a}$ Nina Čelesnik $^{b}$ Mitja Košnik $^{b}$ Peter Korošec $^{b}$ \\ ${ }^{a}$ Department of Pediatrics, University Medical Center, Maribor, and ${ }^{b}$ Laboratory for Clinical Immunology and \\ Molecular Genetics, University Clinic of Respiratory and Allergic Diseases, Golnik, Slovenia
}

\section{Key Words}

Basophil sensitivity · Peanut sensitization in children .

Recombinant peanut allergens

\begin{abstract}
Background: Peanut sensitization is common in children. However, it is difficult to assess which children will react mildly and which severely. This study evaluated the relevance of basophil allergen sensitivity testing to distinguish the severity of peanut allergy in children. Methods: Twentyseven peanut-sensitized children with symptoms varying from mild symptoms to severe anaphylaxis underwent peanut CD63 dose-response curve analysis with the inclusion of basophil allergen sensitivity calculation (CD-sens) and peanut component immunoglobulin E (lgE) testing. Results: Eleven children who had experienced anaphylaxis to peanuts showed a markedly higher peanut CD63 response at submaximal allergen concentrations and CD-sens (median 1,667 vs. $0.5 ; p<0.0001$ ) than 16 children who experienced a milder reaction. Furthermore, a negative or low CD-sens to peanuts unambiguously excluded anaphylactic peanut allergy. Children with anaphylaxis have higher levels of Ara $h$ 1, 2, 3 and $9 \operatorname{lgE}$, but comparable levels of IgE to Ara $\mathrm{h} 8$ and whole-peanut extract. The diagnostic specificity calculated with a receiver operating characteristic analysis reached
\end{abstract}

\section{KARGER}

(C) 2013 S. Karger AG, Basel

$1018-2438 / 13 / 1624-0310 \$ 38.00 / 0$

E-Mail karger@karger.com

www.karger.com/iaa
100\% for CD-sens and 73\% for Ara h 2. Conclusions: We demonstrated that severe peanut allergy is significantly associated with higher basophil allergen sensitivity. This cellular test should facilitate a more accurate diagnosis of peanut allergy.

(c) 2013 S. Karger AG, Basel

\section{Introduction}

Peanut allergy is one of the most common food allergies. A considerable number of children with positive specific immunoglobulin E (sIgE) and positive skin prick test (SPT) are asymptomatic or have a mild clinical picture [1-4]. This can lead to unnecessary avoidance of peanuts in food [5-7].

IgE analysis of peanut allergen components such as Ara $h 1,2,3$ and 9 can only partially designate patients truly allergic to peanuts [8-10]. Others mainly sensitized to the Bet $\mathrm{v} 1$ analog Ara $\mathrm{h} 8$ express milder or no symptoms and usually have a clinical allergy to pollen allergens [11-14]. A double-blind, placebo-controlled food challenge, which is regarded as the gold standard [14], is still required to confirm peanut allergy. Nevertheless, this challenge is difficult to perform in daily practice because it must be conducted in hospital settings, it is time 
consuming and it is associated with the risk of anaphylaxis.

Activation of allergic inflammatory effector cells (mast cells and basophils) is the key event during the development of allergic symptoms. Thus, the basophil activation test (BAT) may offer a clinical answer to an allergen [15] and a complement to the severity of the clinical picture. There are few studies that perform BATs in peanut food allergy $[16,17]$.

For this reason, we included various peanut-sensitized children, evaluated their basophil allergen sensitivity to peanut allergen and then related this cellular sensitivity to the severity of clinical reaction as well as to the sIgE reactivity to peanut allergen components.

\section{Material and Methods}

\section{Study Population}

All children were recruited from the Department of Pediatrics of the University Medical Center in Maribor, northeastern Slovenia. The inclusion criteria were children with unequivocal ingestion of peanut and development of clinical symptoms of anaphylaxis defined according to the international criteria reported by Sampson et al. [18], oral allergic syndrome (OAS), eczema worsening, abdominal cramps or other symptoms related to peanut allergy (skin, respiratory, cardiovascular or gastrointestinal symptoms). The symptoms were described by the physician experienced with allergic reactions in children and confirmed in their medical records. A convincing clinical reaction was any of the described symptoms presented within $1 \mathrm{~h}$ of peanut ingestion. Additionally, we studied those children with positive sIgE antibodies (sIgE-ab) to peanuts and/or a positive peanut SPT. A total of 27 children were included (median age 9 years, 20 boys), 11 with a history of anaphylaxis [18] and 16 with milder clinical symptoms when they consumed peanuts (e.g., isolated eczema worsening with itching, redness, OAS or abdominal cramps). We also collected data on pollen allergies, early sensitization to foods and atopy in relatives.

The study protocol was approved by the Slovenian National Medical Ethics Committee (KME160/07/10), and all parents gave their informed consent.

\section{Specific IgE Measurements and SPT}

SPT is considered valid when the mean wheal diameter is $\geq 3 \mathrm{~mm}$. The levels of sIgE-ab to Ara h 1, 2, 3, 8 and 9 as well as to Bet v 1, Phl p 7 and Phl p 1-5 were quantified using the CAP FEIA system (Phadia, Uppsala, Sweden). A positive test was defined as an IgE-ab level $>0.35 \mathrm{kU} / \mathrm{l}$.

\section{Basophil Activation Tests}

BATs were performed as described previously $[19,20]$. Briefly, whole-blood samples were incubated with various concentrations of an extract PBS of crude peanuts (CP; final concentrations from 3,000 to $0.003 \mathrm{ng} / \mathrm{ml}$ ) or commercially available peanut allergen (commercial extract, CE; Bühlmann Laboratories, Schönenbuch, Switzerland; final concentrations from 30 to $0.3 \mathrm{ng} / \mathrm{ml}$ ) and posi-

Basophil Sensitivity Testing and Peanut Allergy tive controls, $0.55 \mu \mathrm{g} / \mathrm{ml}$ of anti-FceRI mAb (Bühlmann Laboratories) and $2 \mu \mathrm{M}$ fMLP (Sigma-Aldrich, St. Louis, Mo., USA) at $37^{\circ} \mathrm{C}$ for $15 \mathrm{~min}$.

The basophil allergen-specific sensitivity was evaluated by comparing basophil CD63 responses at submaximal allergen concentrations [21] and by CD-sens analyses [21, 22].

\section{Statistical Analysis}

The results are presented as medians and interquartile ranges. Data distribution was calculated using the Shapiro-Wilk test. Depending on the distribution of the data, we used either ANOVA or the Mann-Whitney test. Fisher's exact test was used to compare the categorical data between groups. Correlation coefficients were calculated using Pearson's correlation coefficient. A receiver operating characteristic (ROC) analysis was performed with test results and presented graphically and as area under the curve (AUC) with a $95 \%$ confidential interval. Significance was considered as $p<$ 0.05 . Statistical analysis was carried out using GraphPad Prism 5.

\section{Results}

\section{Demographic and Clinical Data}

Anaphylaxis and non-anaphylaxis children were comparable according to age, sex, early sensitization to food, pollen allergy, peanut SPT positivity, atopy in relatives, and abdominal cramps, OAS and atopic dermatitis (table 1). Children in the non-anaphylactic group expressed only minor symptoms, they were monosymptomatic or had mostly skin problems (worsening of atopic dermatitis). However, the anaphylaxis group had more oral symptoms after peanut ingestion $(\mathrm{p}=0.033)$ and less eczema worsening $(\mathrm{p}=0.008)$. The observed children with anaphylaxis had no abdominal cramps, comparable to the non-aphylactic group (table 2).

\section{CD63 Basophil Response to Peanut Allergens}

The CD63 basophil response was performed with CP and $\mathrm{CE}$ for the anaphylaxis and non-anaphylaxis groups (table 3; fig. 1, 2). With CP stimulation, the CD63 basophil response was significantly higher for anaphylactic patients (fig. 2a) at concentrations of $0.3(\mathrm{p}<0.0001), 30$ $(\mathrm{p}<0.0001)$ and $3,000 \mathrm{ng} / \mathrm{ml}(\mathrm{p}=0.03)$, and the same was true for CE at concentrations of $3(\mathrm{p}=0.001)$ and $30 \mathrm{ng} /$ $\mathrm{ml}(\mathrm{p}<0.0001)$ compared to non-anaphylactic patients (fig. 2b). There were no statistical differences in the lowest concentrations of CP and CE $(\mathrm{p}=\mathrm{NS})$. The basophil responses to positive control anti-FceRI and fMLP were highly comparable between the anaphylaxis [FceRI median 94.5, range (Q1-Q3) 88.7-98.6\%; fMLP median 34.9 , range $28-66.2 \%]$ and the non-anaphylaxis group (FceRI median 92.1, range 67.5-97.6\%; fMLP median 34, range $20.6-49.3 \%)$. 
Table 1. Clinical characteristics of the patients

\begin{tabular}{|c|c|c|c|c|c|c|c|c|c|}
\hline $\begin{array}{l}\text { Patient } \\
\text { No. }\end{array}$ & $\begin{array}{l}\text { Age, } \\
\text { years }\end{array}$ & $\begin{array}{l}\text { Time from the } \\
\text { last symptom } \\
\text { onset, months }\end{array}$ & Anaphylaxis & $\begin{array}{l}\text { Adrenalin } \\
\text { treatment, } \mathrm{n}\end{array}$ & $\begin{array}{l}\text { Atopic } \\
\text { dermatitis } \\
\text { worsening }\end{array}$ & $\begin{array}{l}\text { Abdominal } \\
\text { cramps }\end{array}$ & OAS & $\begin{array}{l}\text { Admitted to } \\
\text { hospital, } \mathrm{n}\end{array}$ & $\begin{array}{l}\text { Peanut } \\
\text { diet }\end{array}$ \\
\hline 2 & 16 & 6 & yes & 2 & no & no & yes & 2 & yes \\
\hline 3 & 11 & 34 & yes & 6 & no & no & yes & 3 & yes \\
\hline 4 & 3 & 2 & yes & 4 & no & no & yes & 4 & yes \\
\hline 6 & 1 & 2 & yes & 1 & no & no & yes & 1 & yes \\
\hline 7 & 6 & 4 & yes & 1 & no & no & yes & 1 & yes \\
\hline 8 & 7 & 56 & yes & 1 & no & no & no & 1 & yes \\
\hline 9 & 14 & 120 & yes & 1 & no & no & yes & 1 & yes \\
\hline 10 & 1 & 2 & yes & 1 & yes & no & no & 1 & yes \\
\hline 11 & 1 & 2 & yes & 1 & no & no & no & 1 & yes \\
\hline 16 & 3 & 6 & no & no & yes & no & yes & 2 & yes \\
\hline 17 & 10 & 3 & no & no & yes & no & yes & 1 & no \\
\hline 18 & 4 & 8 & no & no & no & yes & no & 2 & yes \\
\hline 19 & 12 & 5 & no & no & no & yes & no & 3 & yes \\
\hline 20 & 14 & 9 & no & no & no & yes & no & 1 & no \\
\hline 21 & 15 & 14 & no & no & no & yes & no & 3 & yes \\
\hline 22 & 11 & 6 & no & no & yes & no & no & 1 & no \\
\hline 23 & 18 & 7 & no & no & no & yes & no & 0 & yes \\
\hline 24 & 13 & 5 & no & no & yes & no & no & 0 & yes \\
\hline 25 & 13 & 2 & no & no & no & yes & no & 2 & yes \\
\hline 26 & 12 & 3 & no & no & yes & no & no & 0 & no \\
\hline 27 & 10 & 7 & no & no & yes & no & no & 2 & no \\
\hline
\end{tabular}

\section{CD-Sens Results}

In the anaphylaxis group, CD-sens was markedly higher, with a median of 1,667 [range (Q1-Q3) 1,000333,333 ] with CP stimulation, and with CE stimulation, there was a median of 10 (range 6.2-21.7). With CP stimulation, the non-anaphylaxis group showed a median of 0.5 (range $0.2-0.88$ ), and with CE stimulation, the median was 0 (range $0-2.4 ; \mathrm{p}<0.0001$ for $\mathrm{CP}$ and $\mathrm{CE})$. CD-sens in non-anaphylactic children was 3,000 times (for CP) and 10 times (for CE) lower than in anaphylactic children. Interestingly, there were no Ara h 2 negative children in the anaphylaxis group; all belonged to the non-anaphylaxis group and had a lower CD-sens than Ara h 2 positive children (CD-sens for CP: Ara h 2 positive, median 1,333, range $52.8-25,625$, vs. Ara $h 2$ negative, median 0.25 , range $0.25-0.5 ; \mathrm{p}<0.0001$ ) (fig. 3).

We also analyzed the correlation between CD-sens results and Ara h 2 levels. With CP stimulation, there was no correlation between Ara h 2 and CD-sens ( $\mathrm{r}=0.3, \mathrm{p}=$ 0.2 ), but we confirmed a positive correlation for stimulation with $\mathrm{CE}(\mathrm{r}=0.7, \mathrm{p}=0.0026)$. There was also a significant correlation between $\mathrm{CD}$-sens for stimulation with CP and CE $(r=0.54, p=0.02)$.

Finally, we performed ROC analysis for CD-sens (fig. 4). For CP simulation, the AUC was 0.96 and the $\mathrm{p}$ value $<0.0001$. The optimal recalculated threshold was $>27.8$, with a sensitivity of $88 \%$ and a specificity of $100 \%$. For CE simulation, the AUC curve was 0.98 and the $\mathrm{p}$ value $<0.0001$. The optimal recalculated threshold was $>5.3$, with a sensitivity of $94 \%$ and a specificity of $91 \%$.

\section{Peanut Allergen Components}

In component analysis, all children with anaphylaxis showed positive sIgE reactivity to Ara h 2 and were more often positive to Ara h 1 and 3 . They also had significantly higher sIgE-ab levels to those components $(\mathrm{p}<0.05)$. 
Table 2. Characteristics of the patients studied

\begin{tabular}{|c|c|c|c|}
\hline & \multicolumn{2}{|l|}{ Anaphylaxis } & \multirow[t]{2}{*}{$\mathrm{p}$} \\
\hline & $\begin{array}{l}\text { positive } \\
(\mathrm{n}=11)\end{array}$ & $\begin{array}{l}\text { negative } \\
(\mathrm{n}=16)\end{array}$ & \\
\hline Age, years & $6.2[5.1-11.8]$ & $10.7[2.95-13.75]$ & NS \\
\hline Males & $7(64)$ & $13(81)$ & NS \\
\hline \multicolumn{4}{|l|}{ Patients with pollen } \\
\hline \multicolumn{4}{|l|}{ Early sensitization to } \\
\hline Eczema & $1(9)$ & $10(62.5)$ & 0.008 \\
\hline Abdominal cramps & $0(0)$ & $6(37.5)$ & NS \\
\hline \multicolumn{4}{|l|}{ Oral symptoms after } \\
\hline sIgE to peanut, $\mathrm{kU} / \mathrm{l}$ & $67[1.8-100]$ & $6.9[4.2-8.8]$ & NS \\
\hline Peanut prick positive & $8(89)$ & $5(62.5)$ & NS \\
\hline \multicolumn{4}{|l|}{$\mathrm{rAra} \mathrm{h} 1, \mathrm{kU} / \mathrm{l}$} \\
\hline Median & $5.82[0.0-37.3]$ & $0.0[0.0-0.0]$ & 0.004 \\
\hline Positive results & $6(55)$ & $2(12.5)$ & 0.011 \\
\hline \multicolumn{4}{|l|}{ rAra h 2, kU/l } \\
\hline Median & $57.9[2.1-100]$ & $0.0[0.0-2.9]$ & 0.0003 \\
\hline Positive results & $11(100)$ & $5(31.3)$ & 0.0015 \\
\hline \multicolumn{4}{|l|}{ rAra h 3, kU/l } \\
\hline Median & $1.2[0.0-24.1]$ & $0.0[0.0-0.0]$ & 0.0013 \\
\hline Positive results & $7(58)$ & $1(6.25)$ & 0.0025 \\
\hline \multicolumn{4}{|l|}{ rAra h $8, \mathrm{kU} / \mathrm{l}$} \\
\hline Median & $0.0[0-4]$ & $0.0[0.0-4.6]$ & NS \\
\hline Positive results & $4(33.3)$ & $7(43.75)$ & NS \\
\hline \multicolumn{4}{|l|}{ rAra h 9, kU/l } \\
\hline Median & $0.0[0.0-0.4]$ & $0.0[0.0-0.0]$ & NS \\
\hline Positive results & $3(25)$ & $0(0)$ & 0.0267 \\
\hline \multicolumn{4}{|l|}{ rPhl p 7, kU/l } \\
\hline Median & 0 & 0 & NS \\
\hline Positive results & $0(0)$ & $0(0)$ & NS \\
\hline \multicolumn{4}{|l|}{ rPhl p 1-5, kU/l } \\
\hline Median & $67.2[22.2-95.7]$ & $100[62.5-100]$ & NS \\
\hline Positive results & $4(33.3)$ & $11(68.75)$ & NS \\
\hline \multicolumn{4}{|l|}{ rBet v $1, \mathrm{kU} / \mathrm{l}$} \\
\hline Median & $0.6[0.0-18.3]$ & $2.0[0.0-32.3]$ & NS \\
\hline Positive results & $5(41.7)$ & $8(50)$ & NS \\
\hline
\end{tabular}

Values are given as $\mathrm{n}(\%)$ or medians [Q1-Q3].

Only children with anaphylaxis also had positive responses to Ara h 9. There were no differences in Ara h 8, Phl $\mathrm{p} 1-5$, Phl p 7 (all negative) and Bet v 1 levels ( $\mathrm{p}=\mathrm{NS}$; table 2).

In the Ara h 2 ROC analysis, the AUC was 0.9 and the $\mathrm{p}$ value 0.0004 . An optimal recalculated threshold was
$>5.3 \mathrm{kU} / \mathrm{l}$, with a sensitivity of $94 \%$ and a specificity of only $73 \%$. For Ara h 1 and 3 testing, the AUC was 0.74 and $0.8(\mathrm{p} \leq 0.3)$, and the recalculated threshold was $>3.6$ and $>1 \mathrm{kU} / \mathrm{l}$, with a sensitivity of $100 \%$ but a specificity of only 55\%, respectively (fig. 4). ROC analysis for peanut sIgE showed an AUC of $0.68(\mathrm{p}=\mathrm{NS})$, and the recalculated threshold was $>15 \mathrm{kU} / \mathrm{l}$, with a sensitivity of $81 \%$ and a specificity of only $64 \%$.

\section{Discussion}

This study investigated the relation between clinical allergy and basophil sensitivity to peanuts. We showed that increased basophil allergen sensitivity significantly correlates with the severity of the clinical reaction and that very low or negative basophil sensitivity completely excludes clinically relevant peanut allergy. Furthermore, we also demonstrated that BAT has higher diagnostic specificity with comparable sensitivity than IgE testing for major peanut allergen components.

In daily clinical practice, the diagnosis of peanut allergy is generally based on the case history and the presence of peanut-specific IgE or a positive SPT. Peanut SIgE or the SPT is a proof of sensitization to peanuts but does not equate with clinical allergy. Previous studies related clinical symptoms and the higher level of sIgE/SPT to peanuts with peanut allergy, but this prediction performs suboptimally $[23,24]$. Therefore, sIgE to peanut components Ara h 1, 2, 3, 8 and 9 were recently introduced in clinical practice, with Ara h 2 as the clinically most important predictor $[4,8-11,25]$. Nevertheless, a recent update of a diagnostic prediction model for peanut allergy showed that even after the addition of peanut components, up to $50 \%$ of patients still require a food challenge [26].

Studies that evaluate the clinical relevance of BAT in food allergies have been described in recent years [15, $16,27]$. Therefore, we investigated whether BAT could increase our diagnostic accuracy by improving the discrimination between mild or irrelevant and severe peanut allergy. In our study, BAT was used to analyze the cellular sensitivity to peanuts by comparing the responses between different submaximal allergen concentrations $[17,19]$ and by calculating CD-sens $[15,28]$. In this study, we used two allergen preparations: CP (raw peanuts bought at a store) and CE. Overall, these two allergens gave us comparable clinical and laboratory results. However, there was a high variation in $\mathrm{CD}$-sens for the anaphylaxis group between both extracts used 


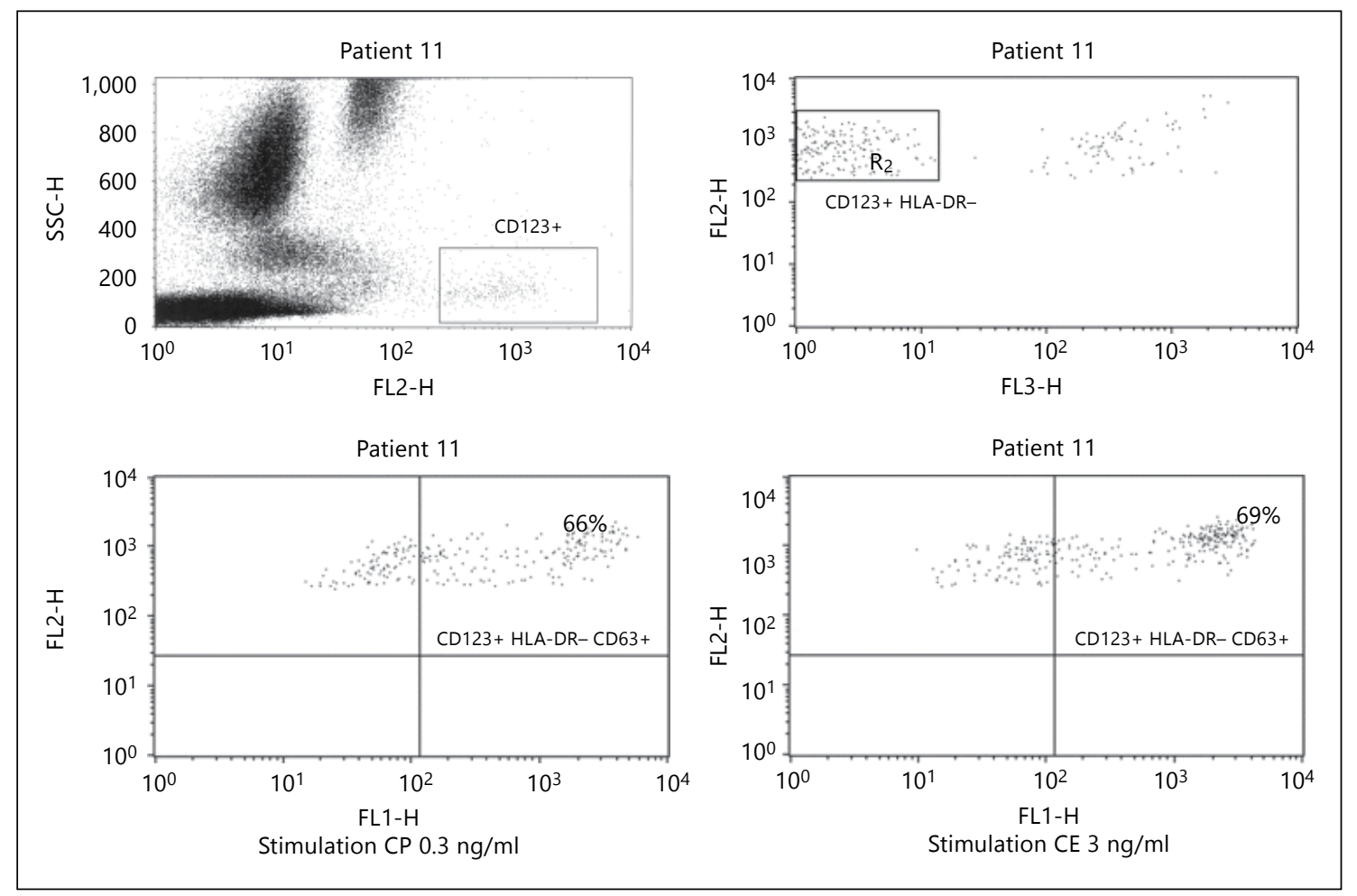

Fig. 1. Flow cytometry dot plot analysis of basophil activation (CD123+ and HLA-DR-) according to the surface expression of CD63 in selected patient No. 11 after stimulation with CP (concentration $0.3 \mathrm{ng} / \mathrm{ml}$ ) and CE (concentration $3 \mathrm{ng} / \mathrm{ml})$.

Table 3. Response in BAT on stimulation with $\mathrm{CP}$ and $\mathrm{CE}$

\begin{tabular}{|c|c|c|c|c|c|c|c|}
\hline & \multicolumn{4}{|c|}{$\mathrm{CP}$ concentration, $\mathrm{ng} / \mathrm{ml}$} & \multicolumn{3}{|c|}{$\mathrm{CE}$ concentration, $\mathrm{ng} / \mathrm{ml}$} \\
\hline & 0.003 & 0.3 & 30 & 3,000 & 0.3 & 3 & 30 \\
\hline $\begin{array}{l}\text { Anaphylaxis } \\
\text { group }\end{array}$ & $8.87(5.6-3.3)^{1}$ & $68.9(61.1-86.7)^{* * *}$ & $85.6(78.7-92.5)^{* * *}$ & $91.1(87-96)^{*}$ & $1.4(0.7-5.6)^{1}$ & $22.3(3.9-38.8)^{* *}$ & $82.4(65.1-91)^{* * *}$ \\
\hline $\begin{array}{l}\text { Non-anaphylaxis } \\
\text { group }\end{array}$ & $6.025(2.1-8.2)$ & $6.89(3.5-13.3)$ & $17.76(8-24.8)$ & $83.56(53.7-96.4)$ & $2.7(2.1-3.3)$ & $2.95(1.8-4.2)$ & $4.7(2.5-13.8)$ \\
\hline
\end{tabular}

(median up to 160 fold). This variation could be explained by the differences in allergenic components in each extract. Namely, the correlation studies between CD-sens and the level of Ara $\mathrm{h} 2 \mathrm{IgE}$ reactivity suggest that the commercial extract is probably based on a higher abundance of the Ara h 2 component than the $\mathrm{CP}$ extract. In the future, it will be important to better standardize the peanut extract and also to evaluate the threshold level for clinically relevant positivity of peanut BAT.

The major finding of this study was that the basophil sensitivity (i.e., CD-sens) to peanuts was markedly higher in anaphylactic than in non-anaphylactic children and that a negative or very low CD-sens unambiguously excludes severe peanut allergy. This observation is in some accordance with the study by Thyagarajan et al. [27] 


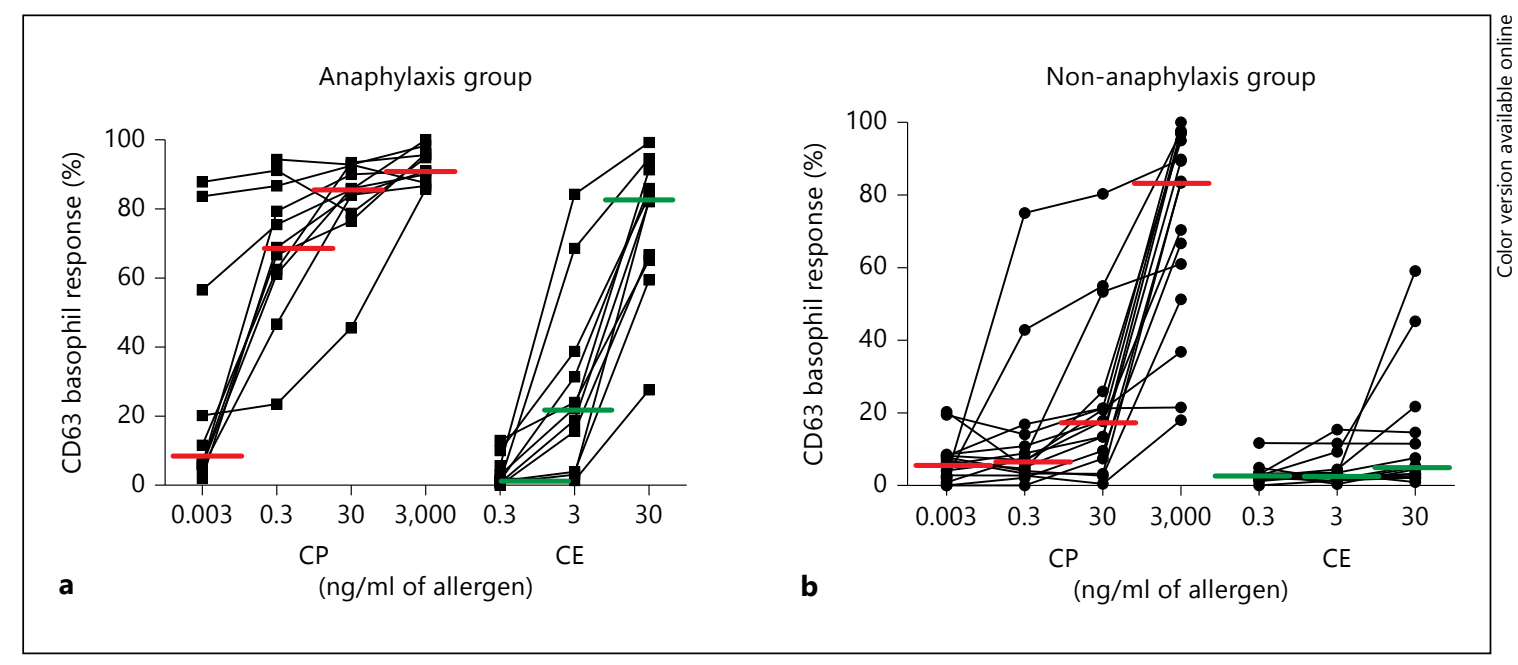

Fig. 2. CD63 basophil response curves after stimulation with $\mathrm{CP}$ (concentration $0.003-3,000 \mathrm{ng} / \mathrm{ml}$ ) and CE (concentration $0.3-30 \mathrm{ng} / \mathrm{ml}$ ) in the anaphylaxis (a) and non-anaphylaxis groups (b).

Fig. 3. $\mathrm{CD}$-sens after stimulation with $\mathrm{CP}$ (a) and CE (b). Open squares represent patients who were negative for Ara h 2. Horizontal lines represent the median with interquartile range.

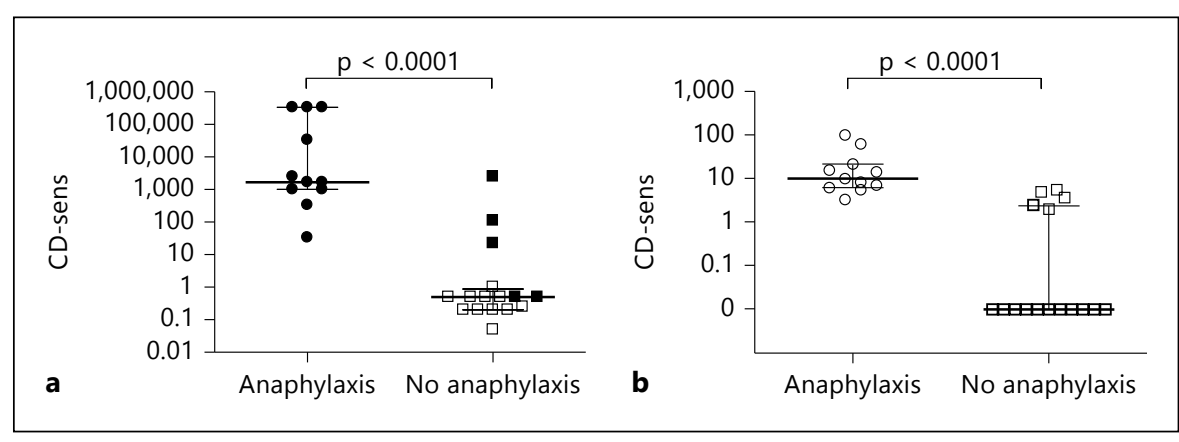

where suppression of basophil CD63 response after peanut oral immunotherapy was demonstrated. In the nonanaphylactic group, there are patients who do not adhere to a strict peanut-free diet which could lead to possible desensitization and significantly lower CD63 response. When we separately analyzed patients maintaining a peanut-free diet in the non-anaphylactic group, no change in this observation was found.

Furthermore, when we investigated the diagnostic value of $\mathrm{CD}$-sens, we showed a larger AUC for CD-sens than for Ara $\mathrm{h} 2 \mathrm{IgE}$ testing. Consequently, the diagnostic specificity of CD-sens was 18 (for $\mathrm{CE}$ ) to $27 \%$ (for $\mathrm{CP}$ ) higher and it reached $100 \%$, comparable to the specificity of Ara h 2 testing (73\%). Glaumann et al. [17] also demonstrated that a negative CD-sens to peanuts excluded peanut allergy and further suggested that the evaluation of basophil sensitivity could be a safe and time-saving complement to provocation testing. It seems that

Basophil Sensitivity Testing and Peanut Allergy

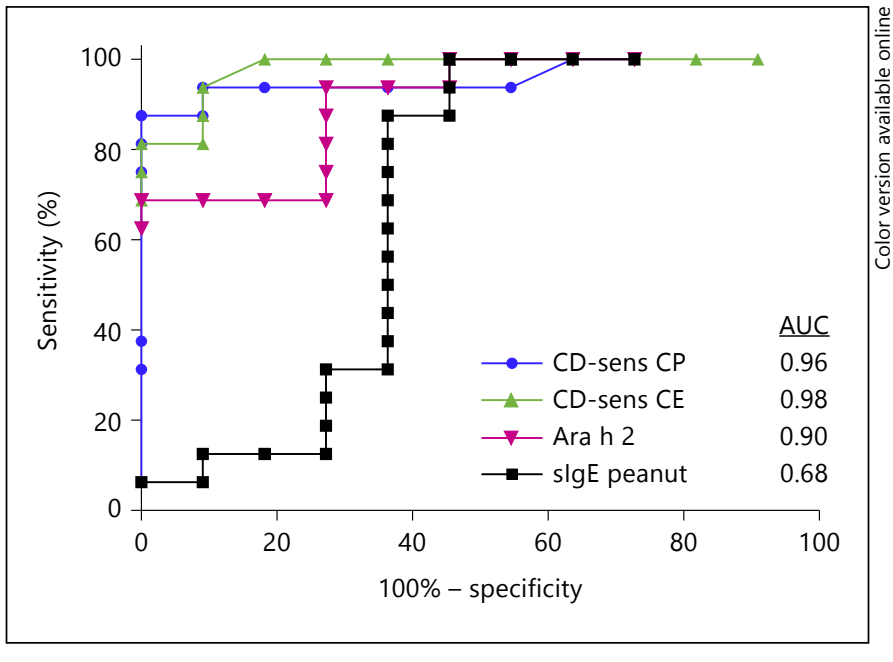

Fig. 4. ROC curve analysis of the sensitivity and specificity of CDsens after stimulation with CP and CE and Ara h 2 and sIgE to peanut testing. 
CD-sens demonstrates better testing discrimination ability than peanut component testing, and thus, the inclusion of this test in diagnostic prediction may further reduce the need for peanut challenges. In addition, recalculated threshold levels for Ara h 2 were higher than in studies to date because they were calculated only in patients with severe symptoms (such as anaphylaxis) [29]. Thresholds for Ara $\mathrm{h} 1$ and 3 have the same value and could help in deciding whether to perform or abandon provocation tests.

The clinical and immunological pattern of IgE sensitization to peanut components was typical for central European countries [11]. Thus, IgE antibodies to Ara h 2, and to a lesser extent to Ara h 1 and 3, were detected in $59 \%$ of children. About one third of Ara h 1-3 positive children did not show systemic reactions. The sensitization rate to the Bet $\mathrm{v} 1$ homolog was evident in $41 \%$ of children and also in one third of anaphylactic children. Isolated Ara h 8 sensitization was only associated with mild symptoms. Interestingly, 3 anaphylactic children were also sensitized to the lipid transfer protein Ara h 9, which is typical for the Mediterranean allergic population [12]. Overall, these data confirmed the allergenicity and importance of Ara h 2 sensitization in the region around Slovenia. In addition, we excluded the importance of sIgE peanut testing.

In conclusion, we have shown that the evaluation of peanut basophil sensitivity might become an important diagnostic tool for discriminating patients with positive sIgE to peanuts, SPT or even sIgE to Ara h 1-3. However, they may have only mild or irrelevant clinical reactions. Future validation studies are needed to reproduce the importance of BAT and $\mathrm{CD}$-sens in peanut allergy.

\section{References}

1 Burks AW: Peanut allergy. Lancet 2008;371: 1538-1546.

2 Wood RA: The natural history of food allergy. Pediatrics 2003;111:1631-1637.

> Patriarca G, Schiavino D, Pecora V, Lombardo C, Pollastrini E, Aruanno A, Sabato V, Colagiovanni A, Rizzi A, De Pasquale T, Roncallo C, Decinti M, Musumeci S, Gasbarrini G, Buonomo A, Nucera E: Food allergy and food intolerance. Intern Emerg Med 2009;4: 11-24.

4 Nicolaou N, Poorafshar M, Murray C, Simpson A, Winell H, Kerry G, Härlin A, Woodcock A, Ahlstedt S, Custovic A: Allergy or tolerance in children sensitized to peanuts: prevalence and differentiation using component-resolved diagnostics. J Allergy Clin Immunol 2010;125: 191-197.

-5 Avery NJ, King RM, Knight S, Hourihane JO: Assessment of quality of life in children with peanut allergy. Pediatr Allergy Immunol 2003; 14:378-382

6 Peeters KABM, Koppelman SJ, van Hoffen E, van der Tas CWH, den Hartog Jager CF, Penninks AH, Hefle SL, Bruijnzeel-Koomen CAFM, Knol EF, Knulst AC: Does skin prick test reactivity to purified allergens correlate with clinical severity of peanut allergy? Clin Exp Allergy 2007;37:108-115.

7 Ben-Shoshan M, Kagan R, Primeau M-N, Alizadehfar R, Turnbull E, Harada L, Dufresne C, Allen M, Joseph L, St. Pierre Y, Clarke A: Establishing the diagnosis of peanut allergy in children never exposed to peanuts or with an uncertain history: a cross-Canada study. Pediatr Allergy Immunol 2010;10:1-7.

8 Niggeman B, Schmitz R, Schlaud M: The high prevalence of peanut sensitization in child- hood is due to cross-reactivity to pollen. Allergy 2011;66:980-981.

-9 Asarnoj A, Östblom E, Ahlstedt S, Hedlin G, Lilja G, van Hage M, Wickman M: Reported symptoms to peanuts between 4 and 8 years among children sensitized to peanut and birch pollen - results from the BAMSE birth cohort. Allergy 2010;65:213219.

$\checkmark 10$ Asarnoj A, Movérare R, Ostblom E, Poorafshar M, Lilja G, Hedlin G, van Hage M, Ahlstedt $\mathrm{S}$, Wickman M: IgE to peanut allergen components: relation to peanut symptoms and pollen sensitization in 8-year-olds. Allergy 2010;65:1189-1195.

11 Vereda A, van Hage M, Ahlstedt S, Ibanez MD, Cuesta-Herranz J, van Odijk J, et al: Peanut allergy: clinical and immunologic differences among patients from 3 different geographic regions. J Allergy Clin Immunol 2011;127:603-607.

$\checkmark 12$ Krause S, Reese G, Randow S, Zennaro D, Quaratino D, Palazzo P, et al: Lipid transfer protein (Ara h 9) as a new peanut allergen relevant for Mediterranean allergic population. J Allergy Clin Immunol 2009;124:771778.

13 Mittag D, Akkerdaas J, Ballmer-Weber BK, Vogel L, Wensing M, Becker WM, et al: Ara $\mathrm{h} 8$, a Bet $\mathrm{v}$ 1-homologous allergen from peanut, is a major allergen in patients with combined birch pollen and peanut allergy. J Allergy Clin Immunol 2004;114:14101417.

14 Niggeman B, Beyer K: Diagnosis of food allergy: toward a standardization of food challenge. J Pediatr Gastroenterol Nutr 2007;45: 399-404.
15 Zidarn M, Košnik M, Šilar M, Grahek A, Korošec $\mathrm{P}$ : Rhinitis symptoms caused by grass pollen are associated with elevated basophile allergen sensitivity and a larger grass-specific immunoglobulin E fraction. Clin Exp Allergy 2011;42:49-57.

16 Ocmant A, Mulier S, Hanssens L, Goldman M, Casimir G, Mascart F, Schandene L: Basophil activation test for the diagnosis of food allergy in children. Clin Exp Allergy 2009;39: 1234-1245.

17 Glaumann S, Nopp A, Johanson SGO, Rudengren M, Borres MP, Nilsson C: Basophil threshold sensitivity, CD-sens, IgE-sensitization and DBPCFC in peanut-sensitized children. Allergy 2012;67:242-247.

18 Sampson HA, Muñoz-Furlong A, Campbell RL, Adkinson NF Jr, Bock SA, Branum A, Brown SG, Camargo CA Jr, Cydulka R, Galli SJ, Gidudu J, Gruchalla RS, Harlor AD Jr, Hepner DL, Lewis LM, Lieberman PL, Metcalfe DD, O'Connor R, Muraro A, Rudman A, Schmitt C, Scherrer D, Simons FE, Thomas S, Wood JP, Decker WW: Second symposium on the definition and management of anaphylaxis: summary report - second National Institute of Allergy and Infectious Disease/Food Allergy and Anaphylaxis Network symposium. Ann Emerg Med 2006;47:373-380.

19 Lalek N, Košnik M, Šilar M, Korošec P: Immunoglobulin G-dependent changes in basophil allergen threshold sensitivity during birch pollen immunotherapy. Clin Exp Allergy 2010;40:1186-1193.

20 Košnik M, Šilar M, Bajrovič N, Mušič E, Korošec P: High sensitivity of basophils predicts side-effects in venom immunotherapy. Allergy 2005;60:1401-1406. 
21 Nopp A, Cardell LO, Johansson SG, Oman H: CD-sens: a biological measure of immunological changes stimulated by ASIT. Allergy 2009;64:811-814.

22 Johansson SG, Nopp A, Oman H, Ankerst J, Cardell LO, Grönneberg R, Matsols H, Rudblad S, Strand V, Stålenheim G: The size of the disease relevant IgE antibody fraction in relation to 'total-IgE' predicts the efficacy of antiIgE (Xolair) treatment. Allergy 2009;64: 1472-1477.

23 Sporik R, Hill DJ, Hosking CS: Specificity of allergen skin testing in predicting positive open food challenges to milk, egg and peanut in children. Clin Exp Allergy 2000;30:15401546 .
24 Wainstein BK, Yee A, Jelley D, Ziegler M, Ziegler JB: Combining skin prick, immediate skin application and specific-IgE testing in the diagnosis of peanut allergy in children. Pediatr Allergy Immunol 2007;18:231-239.

25 Sastre J: Molecular diagnosis in allergy. Clin Exp Allergy 2010;40:1442-1460.

26 Klemans RJB, Otte D, Knol M, Meijer Y, Gmelig-Meyling FH, Bruijnzeel-Koomen CA, Knulst AC, Pasmans SG: The diagnostic value of specific IgE to Ara h 2 to predict peanut allergy in children is comparable to a validated and updated diagnostic prediction model. J Allergy Clin Immunol 2013;131: 157-163.
7 Thyagarajan A, Jones SM, Calatroni A, Pons L, Kulis M, Woo CS, Kamalakannan M, Vickery BP, Scurlock AM, Wesley Burks A, Schreffler WG: Evidence of pathway-specific basophil anergy induced in peanut oral immunotherapy in peanut-allergic children. Clin Exp Allergy 2012;42:1197-1205.

28 Nopp A, Johansson SGO, Ankerst J, Bylin G, Cardell LO, Grönneberg $\mathrm{R}$, Irander $\mathrm{K}$, Palmqvist M, Oman H: Basophil threshold sensitivity: a useful approach to anti-IgE treatment efficacy evaluation. Allergy 2006;61:298-302.

29 Codreanu F, Collignon O, Roitel O, Thouvenot $B$, Sauvage C, Vilain AC, et al: A novel immunoassay using recombinant allergens simplifies peanut allergy diagnosis. Int Arch Allergy Immunol 2011;154:216-226. 